\title{
An Empirical Study of the Impacts of Ambient Temperature on Risk Taking
}

\author{
Xiao Wang \\ Academy of Management, Jinan University, Guangzhou, China \\ Email: philworks16@gmail.com
}

How to cite this paper: Wang, X. (2017). An Empirical Study of the Impacts of Ambient Temperature on Risk Taking. Psychology, 8, 1053-1062.

https://doi.org/10.4236/psych.2017.87069

Received: April 19, 2017

Accepted: May 24, 2017

Published: May 27, 2017

Copyright $\odot 2017$ by author and Scientific Research Publishing Inc. This work is licensed under the Creative Commons Attribution International License (CC BY 4.0).

http://creativecommons.org/licenses/by/4.0/

\section{(c) (i) Open Access}

\begin{abstract}
A large number of studies have found that the ambient temperature shows its inadvertent impact on human's mind and behaviors. There is a reason to believe that risk decision-making, a human advanced cognitive function, will also be affected by the temperature and lead to judgment bias. In this study, the relationship between ambient temperature and risk taking was discussed by manipulating ambient temperature in the laboratory. Participants were instructed to complete the risk taking test (the Balloon Analogue Risk Task, BART) on the computer in three different ambient temperature environments (Hot/Cold/Comfortable). Results indicate that: when ambient temperature is high, the individual will pursue high-risk and high-yield options, and when the ambient temperature is low, the individual tends to be conservative facing risk options.
\end{abstract}

\section{Keywords}

Ambient Temperature, Risk Taking, BART

\section{Introduction}

Temperature has a clear physiological impact on human beings. Different temperatures will bring different feelings: one will feel anxious during the hot weather, and become shivering when it's cold. The concept of "cold" or "hot" can not only be used to describe the temperature, but also often used to describe the person's mental activities or behaviors. Linguists have found that people often use temperature phrases to compare to the inner world of mind. From the point of view of decision-making, we will call people make a choice under the careful thought to be "keep cool". For a choice without any consideration we usually call it "hot-headed". This "cold" and "hot" here does not mean that the individual has an objectively cold and hot feeling, but by using the "cold" and 
"hot" temperature words to express whether or not it is thoughtful while making a choice. Obviously, the temperature of human beings not only has a physiological impact, but also does its effect on human mental function.

The effect of temperature is ubiquitous for human beings, but until recently the psychological effects of temperature began to lead to more and more research and discussion. In many areas there are "temperature effects", including social interaction, consumer behavior, individual's cognitive performance and so on. The "temperature effect" is that physically cold or warm objects prime concepts and behavioral tendencies associated with psychological coldness or warmth (Kang et al., 2011). The study of the "temperature effect" of social behavior is extensive and in-depth, mainly based on the consistency and compensatory hypothesis of metaphor. That is, the physical temperature is a projection to the social emotions, and there is a covariant or compensatory relationship between them. The most famous example is Williams and Bargh (2008) study. Its results found that physical warmth will promote the warmth of interpersonal relationships. In the experiment, participants holding hot coffee were more likely to be a stranger than a researcher who held ice coffee. People who held a hot water bottle were more willing to pick a gift for a friend than for themselves. IJzerman and Semin (2010) designed two experiments to verify the effect of temperature experience on social intimacy. 33 subjects were randomly assigned to touch the cold water or hot water, and then evaluate their intimate relationship with others, and found that individuals holding hot water in the Inclusion of Other in Self Scale score higher. In another experiment, when the subjects and others in the laboratory to sit closer, the subjective feeling of the room temperature is higher. Researchers have found that drinkers who drink cold drinks are more likely to watch love movies with warmth and eroticism (Hong \& Sun, 2012). In the field of consumers' decision, there are some studies to explore the impact of ambient temperature on individual economic behavior. For example, Huang et al. (2014) have shown that warm ambient temperatures can make consumers more willing to refer to others' opinions as a basis for choosing consumer products, forecasting stock prices and gambling in horse racing. Warmth increases the intimacy of the participants to other decision makers, making them more inclined to think that the views of other decision makers are correct and improve compliance with the group. Researchers Zwebner et al. (2013) found that warm temperatures have a premium effect. The physical warmth primes the warmth of the mood, and then promotes a positive response, and ultimately improves the evaluation of the product. There are also many "temperature effects" findings in the most intimate fields associated with decision-making cognition. These were researcher staling a survey of company facilities in different countries, which found that warmth, instead of cold, can promote the productivity of employees (Van De Vliert \& Van Yperen, 1996). It has also been found that the memory performance at $72^{\circ} \mathrm{F}$ (about $22.2^{\circ} \mathrm{C}$ ) reaches the pinnacle (Allen \& Fischer, 1978), and the individual works best at $68^{\circ} \mathrm{F}\left(20^{\circ} \mathrm{C}\right)$, although the most comfortable temperature reported was $80^{\circ} \mathrm{F}$ (about $26.7^{\circ} \mathrm{C}$ ). Hancock et al. 
(2007) studied 291 papers on the effects of temperature on behavioral performance through Meta-Analysis. Analyses confirmed a substantial negative effect on performance associated with thermal stressors. The overall effect size for heat was comparable to that for cold. Cognitive performance was least affected by thermal stressors, whereas both psychomotor and perceptual task performance were degraded to a greater degree.

Although these is rare research focusing on "temperature effect" in the field of behavioral decision-making, but there are some evidence that temperature how to affect people's judgments and selection. Cao and Wei (2005) studied the relationship between temperature and stock returns through a large number of historical data. As a result, the net income of assets was increased when the temperature was low, and the net return on assets was reduced when the temperature was high. The explanation is: extremely hot and very cold weather will increase people's aggression tendency, but extremely hot weather will increase people's sense of coldness in addition. Because the tendency to attack tends to lead to risk appetite for decision making, the net return on assets will be higher; and indifference reduces risk appetite, resulting in lower net asset returns. Porcelli \& Delgado (2009) found that the stress environment adjusted the tendency to taking risks, and this pressure environment and temperature are inseparable. The participants were asked to put their hands in a cold pressure task at $4^{\circ} \mathrm{C}$ and $2^{\circ} \mathrm{C}$ for 2 minutes, followed by operational tests and economic decisions (under loss and benefit scene). The high pressure group (low temperature group) Participants are more conservative in the benefit scene, and more risky in the loss scene. The study of Cheema and Patrick (2012) on consumer decision-making shows that, the warm environment undermines the performance of the individual in complex tasks compared to cold temperature conditions, due to the increase in temperature that causes the resource depletion, Making the individual more dependent on the system 1 (intuition) to make judgments. It suggests that heat load can impair the performance of complex cognitive tasks rather than over-learning or automating tasks (Hancock, 1986) or relatively simple and less demanding tasks (Grether, 1973). There are also some studies have confirmed that the temperature effect only appear on the cognitive-demanding task, but for the simple task has no such effect (Hancock \& Vasmatzidis, 2003; Sellaro, Hommel, Manaï, \& Colzato, 2015). While the cold environment of the individual does not lose the cognitive resources, the individual choice is more inclined to the system 2 (reason). In addition, the study also found that either in the warm or resource loss conditions, people thought innovative radio of pencil shape meant higher risk in complex tasks, therefore, they more inclined to choose the traditional radio. These studies suggest that temperature also affects individual risk preference and risk perception, but there is no clear evidence of the impact of risk decision behavior.

In order to compensate for the "temperature effect" gap in the decision-making field, this study will explore the effect of temperature on individual judgment through experimental research, using complex risk task Balloon Analogue Risk 
Task (BART). This study assumes that the ambient temperature will significantly affect the risk of decision making: the individual will be more conservative when feeling cold; on the contrary, the higher the ambient temperature, the more inclined to seek the risk.

\section{Methods}

\subsection{Participants}

Seventy-one participants provided written consent to the temperature laboratory experiment and received financial compensation for their participation. Participants randomly selected into "hot", "comfortable" and "cold" group by computer, including 25 participants in "hot" condition 31 participants in the "comfort" condition and 24 participants in "cold" condition. They are 37 males and 44 females with an average age of $21.56(\mathrm{SD}=1.483)$.

\subsection{Procedures}

After experiment preparation is complete, the participants are asked to complete the control questionnaire. And then instruct each group into the pre-set temperature of the laboratory. The participants completed the E-prime experiment program on the computers through the computer, including the Positive and Negative Affect Schedule (PANAS), the Balloon Analogue Risk Task (BART). Emotional scale and risk decision-making tasks using a balanced experiment design. After the experiment is completed, participants were asked to fill some relevant demographic information. During the course of the experiment, the subject feeling of ambient temperature (heat or cold) was questioned (seven points), and the participants were given a small amount money as reward.

\subsection{Materials}

Ambient Temperature According to Zhu et al. (2004) on the study of human thermal comfort zone, the Chinese students' population reached $90 \%$ satisfaction in the summer heat comfort zone of $23^{\circ} \mathrm{C}$ to $26.5^{\circ} \mathrm{C}$. Considering the experimental ethics and outdoor temperature, the ambient temperature is set to $22^{\circ} \mathrm{C}$ for cold (low ambient temperature), $26^{\circ} \mathrm{C}$ for comfort (suitable ambient temperature), and $32^{\circ} \mathrm{C}$ for hot (high ambient temperature). In the formal experiment, the outdoor temperature was $26^{\circ} \mathrm{C}$, and the laboratory temperature was adjusted to $32^{\circ} \mathrm{C}$ (experimental condition 1) by laboratory heating equipment, $26^{\circ} \mathrm{C}$ (experimental condition 2) with opening windows, and $22^{\circ} \mathrm{C}$ (experimental condition 3) with air conditioners. During the formal experiment, the temperature was kept as preset. Participants in the course of the experiment need to report the subjective feelings of ambient temperature, using seven points score, 4 points for the comfort, the higher the score that participants feel more hot, the lower the score that participants feel the more cold.

1) Balloon Analogue Risk Task (BART). It's a new task developed by researcher Lejuez et al. (2002) that are closer to human's risk decisions in real life. 
In this task, the computer screen will present a simulated balloon, the participants need to press the button to gradually blow the balloon, each time the balloon will have a certain income, but also the risk of balloon blasting, the greater the balloon, the more likely to get the proceeds Big, but the balloon is blown the higher the risk. If the balloon was blasted, the balloon's income is zero. Each balloon can blow up to 128 times, and participants can choose to stop blowing the balloon at any time to gain the current benefits. This task requires the participants to decide whether to continue to take risks or stop the adventure to obtain a certain benefit. BART test will run 30 times. The BART value is the average inflated number of each balloon (except the blast balloon), i.e. BART value = total cumulative inflatable number/unburned balloon number. The larger the BART value indicates the individual's greater preference of risk taking.

2) Positive and Negative Affect Schedule (PANAS) PANAS used in this study is the version translated into Chinese and revised by researchers Qiu et al. (2008). The scale includes nine positive emotions and negative emotional experience descriptors, requiring the participants to report the emotional experience last week in the 5 -point scale ( 1 = very slight or no, $5=$ very strong).

3) Controlled Variables Including impulse control entries, adventure personality entries. Impulse control entries included six entries from the Barratt Impulsiveness Seale (BIS-11) Chinese version of the questionnaire, used to assess the individual's impulsive personality traits. It is divided into three dimensions: motion impulses, cognitive impulsivity and unplanned impulses. Two entries are extracted from each dimension. The risky personality includes 13 entries, which is composed of "Dare" factor in the $16 \mathrm{PF}$ scale.

\section{Results}

1) Correlation Analysis There was no significant correlation between the three environmental temperatures and the demographic characteristics of the subjects, but correlated with their risk-seeking level. The subjective temperature feeling and the objective ambient temperature were related. Different ambient temperature and dependent variables BART $(r=0.264, p<0.05)$ were significantly correlated. It is obvious that the correlation between different ambient temperature and the risk-seeking level of the subject is obvious and positive correlation. It is worth noting that there is no significant correlation between ambient temperature and positive and negative emotions $(p>0.05)$, indicating that different temperature environments did not significantly affect the mood of the subjects (see Table 1).

2) Manipulation Check Under different environmental conditions, the subjective feeling of preset temperature was significant $(\mathrm{M} 1=5.70 \mathrm{M} 2=4.18 \mathrm{M} 3=$ $2.96)$, and the difference was significant $(p=0.000<0.01)$. Indicating that the subject is really subjective feel hot/comfortable/cold, which verified that the experimental manipulation is effective. In addition, there were no significant difference in sex and age between different groups $(p>0.05)$ and no significant gender and age difference in BART $(p>0.05)$. 
Table 1. Correlation.

\begin{tabular}{|c|c|c|c|c|c|c|c|c|c|c|}
\hline & $\mathbf{M}$ & $\sigma$ & 1 & 2 & 3 & 4 & 5 & 6 & 7 & 8 \\
\hline $\begin{array}{l}\text { 1. Ambient } \\
\text { Temperature }\end{array}$ & 1.980 & 0.790 & & & & & & & & \\
\hline $\begin{array}{l}\text { 2. Temperature } \\
\text { Perception }\end{array}$ & 4.233 & 1.239 & $0.866^{\star *}$ & & & & & & & \\
\hline 3. Hscore & 4.230 & 1.989 & -0.012 & 0.058 & & & & & & \\
\hline 4. BISsocre & 10.270 & 2.720 & 0.218 & 0.296 & -0.178 & & & & & \\
\hline 5. PA & 25.690 & 10.322 & -0.169 & -0.166 & 0.150 & -0.049 & & & & \\
\hline 6. NA & 15.130 & 6.993 & -0.133 & -0.119 & -0.144 & 0.101 & $0.487^{* *}$ & & & \\
\hline 7. Gender & 1.670 & 0.474 & -0.156 & $-0.270^{*}$ & -0.141 & 0.129 & 0.125 & 0.150 & & \\
\hline 8. Age & 21.560 & 1.483 & 0.023 & 0.033 & -0.002 & -0.199 & -0.051 & -0.066 & $-0.249^{*}$ & \\
\hline 9. BART & 65.147 & 21.639 & $0.264^{*}$ & 0.207 & -0.076 & -0.058 & -0.124 & -0.153 & -0.210 & 0.173 \\
\hline
\end{tabular}

3) Variance Analysis After controlling the risky personality, impulses and emotions, study analyzed the variance of the risk indicators under different conditions. BART indicator reflects the tendency of the individual to blow more or less facing potentially explosion of the balloon, which can well represent the individual's willingness to take risks that may be completely lost to achieve higher returns. The results showed that the dependent variable BART $(p=0.033<0.05)$ reached a significant level after controlling irrelevant variable above. This shows that a significant difference was found in the risk preference under different ambient temperature conditions. "Hot" group $(\mathrm{MBART}=75.00)$ prefer high return with high risk than the "comfort" group $($ MBART $=68.01)$, while the "cold" group (MBART $=50.99)$ preferred to take conservative strategies compared with "comfort" group. It can therefore be argued that individuals in a higher temperature environment are more likely to take risky behavior in order to obtain more benefits while in a lower temperature environment, individuals will subconsciously make a conservative choice in order to avoid the unknown risk. It is interesting to note that there was no significant difference in the total gains of the subjects under various experimental conditions through all trials $(p>0.05)$, indicating that the higher/lower risk preference of the subjects was not due to reason to achieve higher returns, which illustrate their risk preference is irrational.

\section{Discussion}

How does temperature affect risk decisions? The study found that emotions do not have a significant impact, so there may be two other psychological mechanisms:

\subsection{Resource Depletion}

The perspective of resource depletion is based on individual cognitive ability is limited, the level of environmental temperature directly affect how much mental resources can be used. 
First, it is related to the direct effect of ambient temperature on the physical body. The human body's normal temperature is $95^{\circ} \mathrm{F}-106^{\circ} \mathrm{F}$ (about $35^{\circ} \mathrm{C}$ $41^{\circ} \mathrm{C}$ ), the body is less tolerant of heat, but has a strong tolerance for cold (Hammel \& Pierce, 1968). Seppänen et al. (2006) found that the cognitive performance of the individual reached its highest point at $72^{\circ} \mathrm{F}$ (about $22.2^{\circ} \mathrm{C}$ ) and continued to decline after more than $75^{\circ} \mathrm{F}$ (about $23.9^{\circ} \mathrm{C}$ ).

The higher temperature will weaken the cognitive performance because the thermal load triggers the Resource Depletion, thus weakening the cognitive performance of the task. Hancock (1986) found that thermal stress consumes mental resources and significantly reduces the performance of individuals in cognitive tasks. Hancock (1989) argues that temperature is hindered cognitive performance by exhausting attention. Hancock interprets the mechanism with the Maximal Adaptability Model, which assumes that heat has a detrimental effect on cognitive performance and is achieved through competition or even depletion of attention resources. Sellaro and other researchers (2015) also found that the individual subjective perception of the preferred temperature is better than the ambient temperature to predict the loss of working memory, and that the main effect of ambient temperature is not significant may be because the temperature setting range is narrow. Cheema and Patrick (2012), from the point of view of complex tasks, have also confirmed that temperature can cause resource depletion.

Individual cognitive judgment mainly depends on the system (system 1 or system 2), but also has a significant impact on the risk tendency. While higher temperatures can exacerbate mental resources, and the extent of resource depletion (especially working memory resources) is closely related to which system is primarily dependent on individual decisions (Cheema \& Patrick, 2012; Evans \& Stanovich, 2013). System 1 is more dependent on intuition, parallel processing and processing faster, do not take up or take up very little psychological resources; system 2 more dependent on rational, serial processing and processing speed is slow, take up a large number of psychological resources. Especially when it comes to working memory, System 1 requires very little working memory, while System 2 requires a certain amount of working memory (Evans \& Stanovich, 2013). When the system 1 is very strong or psychological resource of the decision maker is exhausted, the individual is difficult to analyze in depth, making it difficult for the system 2 to check out the error of the system 1 and finally show the deviation of the decision (Dhar \& Gorlin, 2013). Therefore, when the psychological resources are less, the individual will be more dependent on the decision directed by the system 1 .

Some research evidence suggests that system 1 is often associated with risk seeking. In the case of a standard probabilistic experiment, it is found that individuals who rely on system 1 (heuristic) are more likely to feel better and safer (for example, from a large number of red balls but a low probability (The number of red balls compared to the total of 7:100), rather than choose to increase the probability of winning (from the red ball less than the probability of larger 
bowl, the total number of red balls compared to 1:10) (Denes-Raj \& Epstein, 1994). Two versions of the Columbia Card Task (CCT) paradigm involving complex risk decisions are designed to separate system 1 and system 2, that is, hot versions (Hot CCT) that induce emotional intuitive analysis and induce a thoughtful cold version Cold CCT), trying to show that different systems trigger different risk tendencies. Each time the risky cards turning of the hot version will receive immediate feedback and can be terminated at any time, the cold version only makes one-off decisions on all options to get a total result feedback. It was found that teenagers showed more risk seeking and simple use of information in the hot version (mainly system 1 related), but did not appear in the cold version (mainly system 2 related) (Figner, Mackinlay, Wilkening, \& Weber, 2009).

Thus, since the heat load will reduces the resources that can be used to perform cognitive tasks, the system 2 , which requires a higher mental resource, may be suppressed by resource depletion, making the individual more dependent on the system 1, and thus difficult to rationally assess the risks and benefits that lead to individual risk seeking.

\subsection{Embodied Cognition}

Embodied theory suggests that abstract concepts (such as psychological warmth) are rooted in concrete experiences (such as the warmth of the body) (Lakoff \& Johnson, 1999). Cognitive inputs are stored in the sensory system of the brain, capturing the information perceived by the body in the environment, and repeated experiences create a covariant between the real sensory information and abstract concepts. When the information is subsequently evoked, the process of thinking involves perceived simulations that evoke the physical and environmental experience that has been established (Barsalou, 1999; Schubert, 2005). The "cold" and "hot" sensory experiences correspond to the "cold" and "hot" experiences of mental activity, which exist in the cognitive level. By manipulating sensory, perceptual or other mental states, the social information in the process of participation in the process of interpretation, memory and judgment can be consistent with the metaphor of the changes, which appeared metaphor consistent effect (see Landau et al., 2010). From this point of view, we can deduce that: "calm" decision-making may be associated with the body's cold temperature experience has a coherent link, the temperature environment in the decision-making effect of the two-way, not only the physical state under the influence of ambient temperature may affect the risk Decision making, and on the contrary the individual cannot "keep cool" in judgment will feel physically hot.

\section{Generally Discussion}

This study indicates that physical high temperature will cause the individual to carry out the task of adventure that will be greedier and regardless of the risk, and make the individual biased in favor of choosing to obtain more secure low yield in low temperature environment. This suggests that ambient temperature, as a seemingly unobtrusive factor, affects individual judgment and decision- 
making in unconsciousness, which is consistent with the extra risk of shopping in a warm environment (Cheema \& Patrick, 2012). As mentioned above, there is little research to explore the effect of temperature on the decision-making of gains and losses, and this study fills this gap. This study uses the BART task of dynamic decision-making, which has high ecological validity and can simulate the decision-making behavior of real scene well. In addition, this study confirms the one-way causal relationship between temperature and decision-making, and provides a practical direction for further study of the underlying psychological mechanism.

In conclusion, in a high temperature environment, the individual will make a risk-taking decision, and pursue the high risk and high yield; in low temperature environment, the individual will make a more conservative choice, and prefer the low risk and low yield.

\section{References}

Allen, M. A., \& Fischer, G. J. (1978). Ambient Temperature Effects on Paired Associate Learning. Ergonomics, 21, 95-101. https://doi.org/10.1080/00140137808931700

Barsalou, L. W. (1999). Perceptual Symbol Systems. Behavioral and Brain Sciences, 22, 577-660. https://doi.org/10.1017/s0140525x99002149

Cao, M., \& Wei, J. (2005). Stock Market Returns: A Note on Temperature Anomaly. Journal of Banking \& Finance, 29, 1559-1573.

Cheema, A., \& Patrick, V. M. (2012). Influence of Warm versus Cool Temperatures on Consumer Choice: A Resource Depletion Account. Journal of Marketing Research, 49, 984-995. https://doi.org/10.1509/jmr.08.0205

Denes-Raj, V., \& Epstein, S. (1994). Conflict between Intuitive and Rational Processing: When People Behave against Their Better Judgment. Journal of Personality and Social Psychology, 66, 819-829. https://doi.org/10.1037/0022-3514.66.5.819

Dhar, R., \& Gorlin, M. (2013). A Dual-System Framework to Understand Preference Construction Processes in Choice. Journal of Consumer Psychology, 23, 528-542.

Evans, J. St, B. T., \& Stanovich, K. (2013). Dual-Process Theories of Higher Cognition: Advancing the Debate. Perspectives on Psychological Science, 8, 223-241.

https://doi.org/10.1177/1745691612460685

Figner, B., Mackinlay, R. J., Wilkening, F., \& Weber, E. U. (2009). Affective and Deliberative Processes in Risky Choice: Age Differences in Risk Taking in the Columbia Card Task. Journal of Experimental Psychology: Learning, Memory, and Cognition, 35, 709730. https://doi.org/10.1037/a0014983

Grether, W. F. (1973). Human Performance at Elevated Environmental Temperatures. Aerospace Medicine, 44, 747-755.

Hammel, H. T., \& Pierce, J. B. (1968). Regulation of Internal Body Temperature. Annual Review of Physiology, 30, 641-710.

https://doi.org/10.1146/annurev.ph.30.030168.003233

Hancock, P. A. (1986). Sustained Attention under Thermal Stress. Psychological Bulletin, 99, 263-281. https://doi.org/10.1037/0033-2909.99.2.263

Hancock, P. A. (1989). A Dynamic Model of Stress and Sustained Attention. Human Factors, 31, 519-537.

Hancock, P. A., \& Vasmatzidis, I. (2003). Effects of Heat Stress on Cognitive Performance: The Current State of Knowledge. International Journal of Hyperthermia, 19, 
355-372. https://doi.org/10.1080/0265673021000054630

Hancock, P. A., Ross, J. M., \& Szalma, J. L. (2007). A Meta-Analysis of Performance Response under Thermal Stressors. Human Factors, 49, 851-877. https://doi.org/10.1518/001872007X230226

Hong, J., \& Sun, Y. (2012). Warm It Up with Love: The Effect of Physical Coldness on Liking of Romance Movies. Journal of Consumer Research, 39, 293-306.

https://doi.org/10.1086/662613

Huang, X. I., Zhang, M., Hui, M. K., \& Wyer Jr., R. S. (2014). Warmth and Conformity: The Effects of Ambient Temperature on Product Preferences and Financial Decisions. Journal of Consumer Psychology, 24, 241-250.

IJzerman, H., \& Semin, G. R. (2010). Temperature Perceptions as a Ground for Social Proximity. Journal of Experimental Social Psychology, 46, 867-873.

Kang, Y., Williams, L. E., Clark, M., Gray, J. R., \& Bargh, J. A. (2011). Physical Temperature Effects on Trust Behavior: The Role of Insula. Social Cognitive and Affective Neuroscience, 6, 507-515.

Lakoff, G., \& Johnson, M. (1999). Philosophy in the Flesh: The Embodied Mind and Its Challenge to Western Thought. New York: Basic Books.

Landau, M. J., Meier, B. P., \& Keefer, L. A. (2010). A Metaphor-Enriched Social Cognition. Psychological Bulletin, 136, 1045-1067. https://doi.org/10.1037/a0020970

Lejuez, C. W., Read, J. P., Kahler, C. W., Richards, J. B., Ramsey, S. E., Stuart, G. L. et al. (2002). Evaluation of a Behavioral Measure of Risk Taking: The Balloon Analogue Risk Task (BART). Journal of Experimental Psychology: Applied, 8, 75-84. https://doi.org/10.1037/1076-898x.8.2.75

Porcelli, A. J., \& Delgado, M. R. (2009). Acute Stress Modulates Risk Taking in Financial Decision Making. Psychological Science, 20, 278-283. https://doi.org/10.1111/j.1467-9280.2009.02288.x

Qiu, L., Zheng, X., \& Wang, Y. (2008). The Revision of Positive Emotion Negative Emotion Scale. Chinese Journal of Applied Psychology, 14, 249-254.

Schubert, T. W. (2005). Your Highness: Vertical Positions as Perceptual Symbols of Power. Journal of Personality and Social Psychology, 89, 1-21. https://doi.org/10.1037/0022-3514.89.1.1

Sellaro, R., Hommel, B., Manaï, M., \& Colzato, L. S. (2015). Preferred, but Not Objective Temperature Predicts Working Memory Depletion. Psychological Research, 79, 282-288. https://doi.org/10.1007/s00426-014-0558-4

Seppänen, O., Fisk, W. J., \& Lei, Q. H. (2006). Effect of Temperature on Task Performance in Office Environment. Lawrence Berkeley National Laboratory.

Van De Vliert, E., \& Van Yperen, N. W. (1996). Why Cross-National Differences in Role Overload? Don't Overlook Ambient Temperature! Academy of Management Journal, 39, 986-1004. https://doi.org/10.2307/256720

Williams, L. E., \& Bargh, J. A. (2008). Experiencing Physical Warmth Promotes Interpersonal Warmth. Science, 322, 606-607. https://doi.org/10.1126/science.1162548

Zhu, N., Lv, S., Liu, J., \& Jiang, W. (2004). Experiment on Human Thermal Comfort Zone. Heating Ventilating \& Air Conditioning, 34, 19-23.

Zwebner, Y., Lee, L., \& Goldenberg, J. (2013). The Temperature Premium: Warm Temperatures Increase Product Valuation. Journal of Consumer Psychology, 24, 251-259. 
Submit or recommend next manuscript to SCIRP and we will provide best service for you:

Accepting pre-submission inquiries through Email, Facebook, LinkedIn, Twitter, etc. A wide selection of journals (inclusive of 9 subjects, more than 200 journals)

Providing 24-hour high-quality service

User-friendly online submission system

Fair and swift peer-review system

Efficient typesetting and proofreading procedure

Display of the result of downloads and visits, as well as the number of cited articles Maximum dissemination of your research work

Submit your manuscript at: http://papersubmission.scirp.org/

Or contact psych@scirp.org 